\title{
Reflets
}

Revue ontaroise d'intervention sociale et communautaire

\section{Legault, Gisèle (2000) (sous la direction de), L'intervention interculturelle, Gaëtan Morin Éditeur, Montréal, Paris, 364 p.}

\section{Anselme Mvilongo}

Volume 7, numéro 1, printemps 2001

Santé mentale et les défis de l’an 2001

URI : https://id.erudit.org/iderudit/026350ar

DOI : https://doi.org/10.7202/026350ar

Aller au sommaire du numéro

Éditeur(s)

Reflets : Revue ontaroise d'intervention sociale et communautaire

ISSN

1203-4576 (imprimé)

1712-8498 (numérique)

Découvrir la revue

Citer ce compte rendu

Mvilongo, A. (2001). Compte rendu de [Legault, Gisèle (2000) (sous la direction de), L'intervention interculturelle, Gaëtan Morin Éditeur, Montréal, Paris, 364 p.] Reflets, 7(1), 257-261. https://doi.org/10.7202/026350ar

Tous droits réservés (C) Reflets : Revue ontaroise d'intervention sociale et communautaire, 2001
Ce document est protégé par la loi sur le droit d'auteur. L'utilisation des services d’Érudit (y compris la reproduction) est assujettie à sa politique d'utilisation que vous pouvez consulter en ligne.

https://apropos.erudit.org/fr/usagers/politique-dutilisation/ 


\section{Legault, Gisèle (2000) (sous la direction de), L'intervention interculturelle, Gaëtan Morin Éditeur, Montréal, Paris, 364 p.}

Lu par Anselme Mvilongo

École de service social, Université Laurentienne

Un petit rappel historique s'impose. En 1981, quand le ministère de l'Immigration du Québec devint le ministère des Communautés culturelles et, avec l'arrivée du document Autant de façons d'être Québécois, le Québec entendait se donner un plan d'action à l'intention des communautés dites culturelles, plan qui poursuivait trois objectifs : 1) assurer le maintien et le développement des communautés dites culturelles et de leur spécificité; 2) sensibiliser les Québécois francophones à l'apport des communautés culturelles au patrimoine commun; 3) favoriser l'intégration de ces communautés dans la société québécoise francophone.

Ce beau plan n'a peut-être pas réussi pleinement à atteindre ses trois objectifs et ce sont les agences de services sociaux, les hôpitaux ainsi que les intervenants qui ont ressenti le désintéressement et le non-recours des immigrants aux services sociaux et de santé.

Cet ouvrage est le fruit des efforts entrepris depuis ce tempslà (une vingtaine d'années) pour sensibiliser et mieux former les intervenants qui travaillent en milieux multiethniques et multiculturels francophones du Québec.

\section{L'ouvrage}

Le livre est le produit d'une douzaine d'auteurs de diverses disciplines et travaillant dans le domaine de l'interculturel. Il commence par un prologue où est longuement décrit le processus 
migratoire sous l'angle des sentiments ressentis par l'immigrant et des transformations de son identité.

L'ouvrage est divisé en deux parties. La première partie, intitulée "Les phénomènes observés en contexte d'immigration", traite d'abord, dans le premier chapitre, de la diversité des visions du monde à travers les cultures. Il s'ensuit une présentation et une élaboration théorique, dans les chapitres 2 et 3 , des mécanismes d'inclusion et d'exclusion à l'œuvre dans la société d'accueil. Le chapitre 4 expose la problématique spécifique des réfugiés et des revendications du statut de réfugié au Canada de même que ses implications pour l'intervention.

La deuxième partie, "Les problématiques particulières et les modes d'intervention", aborde, dans le chapitre 5, les divers modèles de pratiques interculturelles qui se dégagent des écrits principalement américains, français et québécois, sur le sujet, au cours des années 80 et 90 . Le chapitre 6 est destiné à ordonner les informations pertinentes sur une situation en vue d'une orientation d'action appropriée. Le chapitre 7 présente une vision d'une approche interculturelle auprès des migrants. Le chapitre 8 aborde les difficultés d'intervention telles que répertoriées lors des recherches effectuées au début des années 90 . Au chapitre 9 , le génogramme est présenté comme outil d'intervention, outil que l'auteure a trouvé utile dans le contexte d'interventions auprès de réfugiés en phase d'établissement. Le chapitre 10 traite de la pratique interculturelle auprès des jeunes aux prises avec la Direction de la protection de la jeunesse et illustre l'utilisation du génogramme comme outil d'intervention. Le chapitre 11 aborde l'intervention auprès des femmes immigrantes et réfugiées et les problématiques spécifiques qui les touchent, à partir essentiellement du Centre des femmes de Montréal.

Deux chapitres terminent cette partie : le chapitre 12 rend compte des liens entre le champ de l'interculturel et celui de l'ethnopsychiatrie tant en France qu'au Québec. Le chapitre 13 traite finalement de la pratique auprès des jeunes dans une perspective ethnopsychiatrique. 


\section{L'objectif du livre}

Selon les auteurs, lesquels proviennent de différentes disciplines et de différents champs de pratique, ce livre se veut un instrument de travail pour les intervenants et les étudiants des domaines de la santé et des services sociaux. Il vise à leur fournir certains instruments théoriques et pratiques pouvant leur être utiles dans leur pratique professionnelle et communautaire.

En effet, le praticien en milieu multiethnique et multiculturel doit pouvoir jouir d'un éventail de connaissances sur l'histoire de l'immigration et les politiques dans ce domaine, sur les problématiques sociales les plus importantes touchant les immigrants et les réfugiés ainsi que sur les mécanismes d'inclusion ou d'exclusion des migrants.

L'intervenant social doit, en outre, avoir une compréhension profonde de sa propre culture et de l'influence de celle-ci sur ses modes de pensée, ses attitudes et ses comportements, et il doit posséder une ouverture et un intérêt pour la culture de l'autre. De plus, il doit connaitre les divers processus et modèles d'intervention afin d'adopter les stratégies les plus appropriées pour venir en aide aux individus, aux familles ou aux groupes qui en ont besoin.

\section{Le contenu}

Dans cet ouvrage qui porte sur l'interculturel, les auteurs tentent d'abord plusieurs définitions de la notion même de l'interculturel avant de passer à la diversité des visions du monde selon les cultures et à l'observation des phénomènes en contexte d'immigration. Cette observation les a amenés à proposer différents modèles d'intervention selon les problématiques rencontrées. Après avoir montré les problèmes généraux présentés par différentes cultures en présence, les auteurs, préoccupés par les problématiques présentées par les immigrants et les réfugiés, tentent de montrer 
comment identifier les problèmes spécifiques de ces derniers dans le contexte de la société d'accueil.

Pour ce faire, les auteurs ciblent des problématiques spécifiquement identifiées aux populations immigrantes et réfugiées, notamment les jeunes immigrants aux prises avec la Direction de la protection de la jeunesse. Les auteurs tentent d'élucider les notions de droit et d'intérêt de l'enfant, les notions d'autorité parentale et de compromis entre parents et enfants; ils tentent également d'éclaircir les procédures légales de l'application de la loi, les enjeux interculturels de l'adolescence, le clivage et la double mésadaptation, l'affiliation et l'intervention auprès des femmes immigrantes et réfugiées avec les problématiques spécifiques qui les touchent telles les réalités des femmes et leur famille ainsi que la pratique auprès des jeunes dans une perspective ethnopsychiatrique.

La richesse du contenu de cet ouvrage réside avant tout dans le fait que les théories sont immédiatement étayées par l'analyse de cas pratiques. Cet instrument d'intervention fait appel et suppose beaucoup de connaissances, beaucoup de savoir-faire et de savoir être chez l'intervenant ou l'étudiant, mais pour le bénéfice de l'intervenant ou de l'étudiant, certains concepts clés comme la décentration auraient pu être développés davantage. Que dire de la notion d'identité si essentielle dans une rencontre entre deux cultures différentes? Car dans toute intervention dite interculturelle, ce sont bien deux identités culturelles en interaction, et comme telle, aucune n'est supérieure à l'autre. Pourquoi la notion d'identité culturelle est-elle passée sous silence dans cet ouvrage? Faudrait-il comprendre que c'est l'intervenant qui distribue les identités à ses clients allogènes? L'important effort de reformulation substantielle et de saisie de soi en tant qu'identité face à l'autre revient donc au lecteur ou à l'utilisateur de cet ouvrage.

\section{Conclusion}

Ce volume constitue néanmoins un bon instrument pour les intervenants et les étudiants dans les différents domaines des 
relations humaines et devrait permettre d'amorcer une réflexion et une analyse en profondeur des notions et des concepts essentiels en interculturel : l'identité culturelle, l'ethnocentrisme culturel (notion qui n'apparait pas explicitement dans le texte), le double concept de la centration et de la décentration culturelle sans l'application duquel toute intervention et toute socialisation ne sont qu'une manœuvre d'uniformisation et d'homogénéisation à la culture dominante, ne respectant ni la culture, ni la personnalité de l'individu que l'on veut aider. Les auteurs ne semblent pas mettre l'accent sur ces concepts essentiels pour une véritable intervention interculturelle. L'interculturel est, non pas une idéologie, mais une réalité dynamique parce qu'il se définit «par rapport à un ensemble de pratiques mises en œuvre pour répondre à des problèmes de terrain».

Je concluerai en rapportant ce qu'a écrit l'une des auteures en citant Ladmiral et Lipiansky : «'interculturel définit moins un champ comparatif où il s'agirait de mettre en regard deux objets, qu'un champ interactif où l'on s'interroge sur les relations qui s'instaurent entre groupes culturellement identifiés». C'est donc dire que l'intervenant ou le formateur de la culture dominante ne devrait pas céder à la tentation de combler un vide chez la personne à aider, ni de tenter de la transformer selon lui, c'est-àdire selon sa vision du monde ou son propre vécu. 